\title{
Entrepreneurship is Manifested in Action
}

\section{Amir Emami*}

Faculty of Management, Kharazmi University, Iran

\begin{abstract}
In this essay I discuss that because of the attribute errors linked to entrepreneurial opportunity, action contributes more insights on creating a venture than a strong idea or opportunity per se. Action can provide idiosyncratic market knowledge as a basis for sound judgment (in opposed to lousy judgment) and the subsequent decisions on whether to invest on an opportunity or not, mainly for the entrepreneurs with limited resources and experience.
\end{abstract}

Keywords: Action; Entrepreneurial opportunities; Idiosyncratic knowledge

\section{Introduction}

A mountain climber was returning to his camp after an intense summiting. He had made some mistakes in forecasting the weather. $\mathrm{He}$ got lost in the mountains due to heavy snowing and fog. He decided to stay in the mountains for one extra day hoping the weather would improve. Conversely, the condition became worse (temperature, fog, and food condition deteriorated). The next day rescue team found him suspended with his rope, frozen and dead just two meters above the ground and only 100 meters away from the camp.

\section{Opportunity, the Spoiled Child of Entrepreneurship}

The above anecdote is an excellent example of entrepreneurial settings where entrepreneurs have to survive in the face of abject uncertainty. Like the real world, entrepreneurs have to find their ways (their opportunities) in the market that is in a dense fog and full of blurs. She may not even know that the success is much closer to her than she thinks.

In modern entrepreneurship literature, entrepreneurs are agents whose primary task is acting in the face of uncertainty to discover, evaluate, and exploit profit opportunities often in the form of new ventures [1-3].

One reason recently entrepreneurship scholars have started to pay attention to "action" is due to the critics on the ontology of entrepreneurial opportunity. In a classic view on the entrepreneurial opportunity, that is favorably evaluation of information pertinent to business situations, which introduces new goods and services that had not previously been noticed by other market participants [4].

He challenges favorability as a natural innateness of opportunity. $\mathrm{He}$ points out that one of the main reasons opportunity has not attained clarity is that opportunity in previous studies often carries the connotation of favorability. He mentions when an opportunity is described as false, illusory, or unfruitful or as bringing losses to the entrepreneur, they often justify that it is the entrepreneur who failed to take the right action or have good judgment about the opportunity (i.e., opportunities are favorable ex-ante). He submits (P. 675):

"[Many] of the problems are inherent in any notion of "opportunity" and therefore inescapable in research under that label. In particular, the favorability connotation of "opportunity" is highly problematic in forward-looking research, i.e., when trying to argue at an early stage how the characteristics of the actor and the "opportunity" will affect action and outcomes... If the rationale is "objectively" favorable outcome prospects, then characteristics of "opportunities" can explain neither inaction nor failure."

As such, if the favorability is deducted from the opportunity, these researches will no longer have reason to use the opportunity label. Hence, the authors mistakenly assume a vis-à-vis situation between opportunity and business success, and the difference between successful and less successful entrepreneur is that the former has exploited more of a given opportunity than the latter. As such, "opportunity" is a favorable condition, regardless of the actor. However, these authors neglected the fact that entrepreneurs create functional relationships among elements - customers, suppliers, production, money, information, and other resources- which require real human actions and interactions to come to fruition [5]. There is no opportunity without creating relationships between these ingredients [5]. This functional kind of relationship is created and organized through subjective processing [6]. However, another attribution error, which is the opposite scenario, also exists when entrepreneurs are assumed to be "great" businessmen [7]. In this attribution error, there is a tendency to praise the entrepreneurs' characteristics or skills and to overlook the enabling force of their environment, as well as external enablers such as regulatory, demographic and social changes [7]. These two attribute errors in entrepreneurship literature are the significant obstacles to the clarity of opportunity construct. For this reason, opportunity label per se is misleading unless entrepreneur evaluates it through interactive feedback loops generated by her actions in the market. Therefore, because of the attribute errors concerning entrepreneurial opportunity, action provides more insights on creating a venture than a strong idea or opportunity per se. I elaborate on this in the next section.

\section{Role of Entrepreneurial Action in Shrinking Uncertainty}

Prior judgment of eventual commercial success is unreliable because intuitive insights cannot be judged right or wrong ex-ante. They are only possibilities [8]. Thus, individuals are inclined to be more effortful, and deliberately control cognitive processes $[9,10]$. Before starting an action, entrepreneurs need to know how much novelty it involves, how much purposefulness of action is required [11], and whether she/he

*Corresponding author: Amir Emami, Faculty of Management, Kharazmi University, Iran, Tel: +982188329220; E-mail: Emami.polito@gmail.com

Recieved January 08, 2018; Accepted January 30, 2018; Published February 06, 2018

Citation: Emami A (2018) Entrepreneurship is Manifested in Action. J Entrepren Organiz Manag 7: 223. doi: 10.4172/2169-026X.1000223

Copyright: (๑) 2018 Emami A. This is an open-access article distributed under the terms of the Creative Commons Attribution License, which permits unrestricted use, distribution, and reproduction in any medium, provided the original author and source are credited. 
has necessary competency to perform it. Besides, how subjective norm props the new value idea $[12,13]$.

In a world of Knightian uncertainty and heterogeneous capital resources with attributes that are subjectively perceived and unknowable ex-ante, some business must shoulder the responsibility of holding, managing, deploying, and redeploying these means in the service of buyer needs [14]. The entrepreneur's job is to formulate and reformulate various capital resources in pursuit of profit situations. Profit situations are those that the entrepreneur is successful in acquiring resources at prices below their realized marginal revenue products [3]. That, in Klein's [14] formulation, is the function of the entrepreneur's good judgment. Klien [14] submits: "Entrepreneurial action is seen as beginning with the entrepreneur's interpretation of current (objective) conditions, his beliefs about possible future states of the world (e.g., a profitable product or venture), and his expectations and confidence in his the ability to bring about that possible future. The entrepreneur then acts (or doesn't act), with success or failure determined ex-post, largely by objective factors."

The difficulty in defining profit situations is that they are unknown [7], because of the immense uncertainty from the time of idea generation to exploitation [15]. For this reason, any profit situation cannot be called opportunity unless post hoc actions take place. Once the idea is generated, individuals intuitively perform a series of activities -as well as trial and errors- to decrease the uncertainty they are bearing. These activities also contribute to the opportunity insights [8], i.e., the initial idea changes over time through a series of new insights [16] (Figure 1).

Opportunity is something personal because it depends on the judgment of whether or not a specific set of circumstance represents an opportunity for a particular person [17]. The systematic models such as Lean Startup, Steve-Blank, and Business Model Canvas are useful tools that contribute to action paradigm I detailed above. From the very early stages of opportunity development they can be applied. When an entrepreneur is testing her hypothesis about the pertinent value proposition and generate the product-fit in the market, these models decrease the blurs and uncertainty that encompass the venture creation.

Furthermore, action can determine the essential attributes of desirability, feasibility, and viability of an opportunity long before the stablishment of the pertinent venture.

A desirable solution is one that customers needs. An analysis of desirability centers on whether the idea is a nice to have or a must have for the customer. Questions like:

- What task aiding customers to complete?

- What does prosperous fulfillment of that task look like for them?

In fact, studying at what they are trying to do and why it is valuable to them, taking their perspectives, and looking at our solution from their eyes. After desirability study entrepreneur would know if she is solving the critical pain points customers encounter. If not, and there are other pain issues that entrepreneurs have not addressed, then she should modify her solution and try to find out a better path.

A feasible solution is about building on the strengths of current operational capabilities. Feasibility study strives to uncover the strengths and weaknesses of a current business or a proposed business venture. Besides, It takes into consideration the opportunities offered by the external enablers e.g., changes to technology, demography, culture, human needs, and wants; institutional framework conditions, macroeconomic conditions and the natural environment [18], entrepreneur's resources, and the consequent success of the venture.

Finally, Viability is a profitable solution, with a sustainable business model. Viability deals with the study of the existing business or proposed venture's sustainability. It defines if the business idea should be accepted or not. Also, It requires dealing with strategies on how to make the venture grow and last. This can be viewed in the profits that the business can make for a particular period.

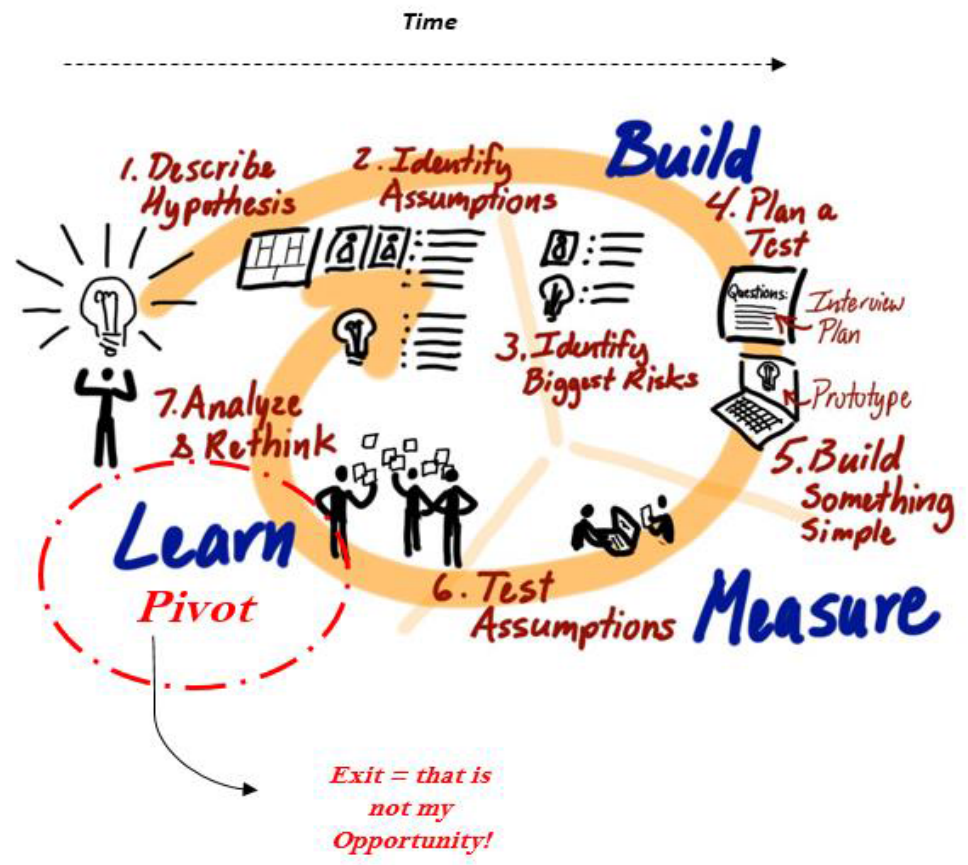

Figure 1: An exemplary model of entrepreneurial action before the establishment of / giving up a venture [A]. 
Last but not the least, whether we want or not, opportunity is the child of entrepreneurship, the beloved and spoiled one. No parents threw out their children just because he/she is not understandable. The action view can reconcile competing accounts of opportunity in entrepreneurship literature (e.g., discovery vs. creation) and let them to be verified from a pragmatic perspective e.g., desirability, feasibility, and viability test.

Action can provide idiosyncratic market knowledge as a basis for sound judgment (in opposed to lousy judgment) and the subsequent decisions on whether to invest in an opportunity or not, mainly for the entrepreneurs with limited resources and experience. That is an essential consideration for the future theoretical developments in the domain of entrepreneurship.

To sum up, I conclude this essay with a quote from Joe Gebbia the co-founder of Airbnb- when he was asked to advise prospective entrepreneurs [19].

Build something. Right now, it's never been easier to make things. It's never been easier to create an app or a website. The resources out there are enormous, and the cost to access them has never been this low. I would encourage them to make stuff. Get your hands as dirty as possible. Throw yourself into an experience of making. Coding, or design, or whatever it is, learn it, and make something. It's not like there have to be 10 million people using it. It might be just your friends or yourself. But you made something, and you shipped it.

\section{References}

1. Dimov D (2010) Nascent entrepreneurs and venture emergence: opportunity confidence, human capital, and early planning. Journal of Management Studies 47: $1123-1153$

2. Emami A (2017) Gender risk preference in entrepreneurial opportunity: evidence from Iran. International Journal of Entrepreneurship and Small Business 30: 147-169.

3. Klein PG (2008) Opportunity discovery, entrepreneurial action, and economic organization. Strategic Entrepreneurship Journal 2: 175-190.

4. Chiles TH, Bluedorn AB, Gupta VK (2007) Beyond creative destruction and entrepreneurial discovery: A radical Austrian approach to entrepreneurship, Organisation Studies 28: 467-493
5. Crawford CG, Dimov D, McKelvey B (2015) Realism, empiricism, and fetishism in the study of entrepreneurship. Journal of Management Inquiry 25: 168-170.

6. Shane S, Venkataraman S (2000) The promise of entrepreneurship as a field of research. Academy of Management Review 25: 217-226.

7. Dimov D (2007) Beyond the single person, single insight attribution in understanding entrepreneurial opportunities. Entrepreneurship Theory and Practice 31: 713-731.

8. Dimov D (2007) From opportunity insight to opportunity intention: the importance of person-situation learning match. Entrepreneurship Theory and Practice 31: 561-583.

9. Emami A, Dimov D (2017) Degree of innovation and the entrepreneurs' intention to create value: A comparative study of experienced and novice entrepreneurs. Eurasian Business Review 7: 161-182.

10. Emami A, Talebi K (2011) Decision Framing and Critical Success Factors of New Product Development. African journal of business management 5: 62336239.

11. Warneryd KE (1988) The psychology of innovative entrepreneurship, in Handbook of Economic Psychology. Handbook of Economic Psychology, pp: 404-447.

12. Emami A, Saghafi F, Zarei B, Ebrahimzadeh M, Davari A (2011) Managerial application of framing effects and mental accounting in network participation. Advances in Production Engineering and Management 6: 57-69.

13. Wood MS, McKelvie A (2015) Opportunity evaluation as future focused cognition: identifying conceptual themes and empirical trends. International Journal of Management Review 17: 256-277.

14. Klein PG (2017) My contributions to entrepreneurship theory, Baylor Business, Entrepreneurship, and Free Entreprise.

15. Knight FH (1921) Risk, Uncertainty and Profit. University of Illinois at UrbanaChampaign's Academy for Entrepreneurial Leadership Historical Research Reference in Entrepreneurship.

16. McMullen JS, Dimov D (2013) Time and the entrepreneurial journey: the problems and promise of studying entrepreneurship as a process. Journal of Management Studies 50: 1481-1512.

17. Mcmullen JS, Shepherd DA (2006) Entrepreneurial action and the role of uncertainty in the theory of the entrepreneur. Academy of Management Review 31: 132-152.

18. Davidsson $P$ (2015) Entrepreneurial opportunities and the entrepreneurship nexus: A re-conceptualization. Journal of Business Venturing 30: 674-695

19. Kolko J (2014) Well-designed: how to use empathy to create products people love. Harvard Business Review Press. 